\title{
Will Hurricanes Like Hurricane Maria Become More Common in the Future?
}

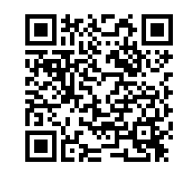

\author{
Ronald T Richards* \\ Ph.D, Universidad del Este, Carolina, Puerto Rico
}

Received: 制 March 21, 2018; Published: 制 April 05, 2018

*Corresponding author: Ronald T Richards, Ph.D, Universidad del Este, Carolina, USA

\section{Opinion}

I teach physics in Puerto Rico. On 20 September 2017, Hurricane Maria, a category 4 storm hit the island. I live in Trujillo Alto and my house was without electricity for 105 days until 3 January 2018. Today there are several hundreds of thousands of people in Puerto Rico who do not have electricity and for those who do have power the system is unstable with frequent blackouts. Hurricane Maria hitting Puerto Rico was part of a hurricane season that included massive destruction in Texas and Florida. Unless you have lived through a similar experience, it is difficult to imagine what Puerto Rico was like in the weeks after the hurricane. If you did not have stockpiled in your house food, water, cash, gasoline, propane, or medicine these things were only available from your neighbors or in very limited quantities in the few stores that were open. There was no telephone service and there were very few first responders to answer your call. For a week and a half after the storm I was a volunteer with the Municipal Emergency Management Office. The day after the storm they had no generator and no communication with the vehicles that left the office. The instruction was return in 3 hours so that we know that you are alive. And it was not only the lack of telephone service. Radio and television stations were going off the air. There were no newspapers, Internet, or postal service. For most people the only connection with the world was an AM radio operated with batteries. And the radio was filled with hospital administrators making a desperate plea for a truck load of Diesel.

How many people died in Puerto Rico from Hurricane Maria? The official answer is 64 and nobody believes it is valid. The news network CNN spoke to about 100 funeral homes and came up with 499. The New York Times newspaper puts the number near 1000. Traditionally in hurricanes, 90 percent of the deaths came from water and not winds. It appears that in Hurricane Maria, that the majority of the deaths were people with a preexisting medical condition who died from a health care system that did not have electricity, telecommunication or transportation. In the San Juan metropolitan area, what were several weeks living without modern society, was several months in the mountainous center of the island where many roads were blocked by landslides. People could wait 6 hours to buy gasoline and then the hour of curfew would arrive, and they would lose their place in the line. There were lines hours long to obtain cash or visit the bank, supermarket, propane, or the pharmacy. Private universities reopened a month after the storm without electricity in the classrooms. Physics labs were modified to do experiments without electronic sensors. Students worked near the windows to have light. Doing a test, cell phones were used as flashlights. The public University of Puerto Rico system and public schools were slower to reopen.

In 1928 a category 5 hurricane hit the Caribbean and Florida. In Puerto Rico it is called San Felipe and in Florida, it is called Lake Okeechobee. The storm killed about 4000 people, mostly in Guadalupe and Florida. The social crisis after the hurricane of 1928 was different than today. It is estimated that less than 10 percent of much smaller population had electricity, telephone, or vehicles that used gasoline and Diesel. The transportation system included carts pulled by horses and oxen. People lived in houses with thatched roofs. In 1929 people were camped everywhere looking for scraps of wood and metal to rebuild their houses. Many people had not rebuilt before the economy collapsed in the Great Depression. Malnutrition was common in Puerto Rico in the 1930s. I have spoken to a man who in 1941 was below the minimum weight to join the United States Army. There is one bright side to Hurricane Maria. I am using data from more than 60 non-pumping observation wells to create a groundwater level index that covers the last 50 years. The goal is an index that is more representative than any single observation well. The good news is that the preliminary results are that Hurricane Maria is the largest recharge event in the last 50 years. Hurricanes are born over the open ocean where the friction is very low. A hurricane is formed over warm water when the atmospheric conditions are just right. The damage from a hurricane is after it forms and then crosses from the ocean to the land. The rising concentration of carbon dioxide in the atmosphere will cause the Earth and its oceans to become warmer. 
Hurricanes are usually born in tropical waters but not directly over the equator and they then travel to higher latitudes. In the process they transport heat away from the equator. One hypothesis is that powerful hurricanes will become most common as the waters of the oceans get warmers. This is a reasonable hypothesis, but it is unproven. The oceans regulate the climate of our planet. A central question for climate change and ocean science is how common will hurricane like Maria be? Will they hit Puerto Rico once every 80 years or once every 8 years?

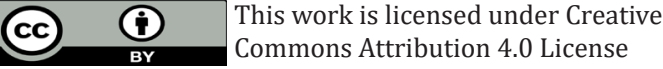

To Submit Your Article Click Here: Submit Article

DOI: 10.32474/MAOPS.2018.01.000113

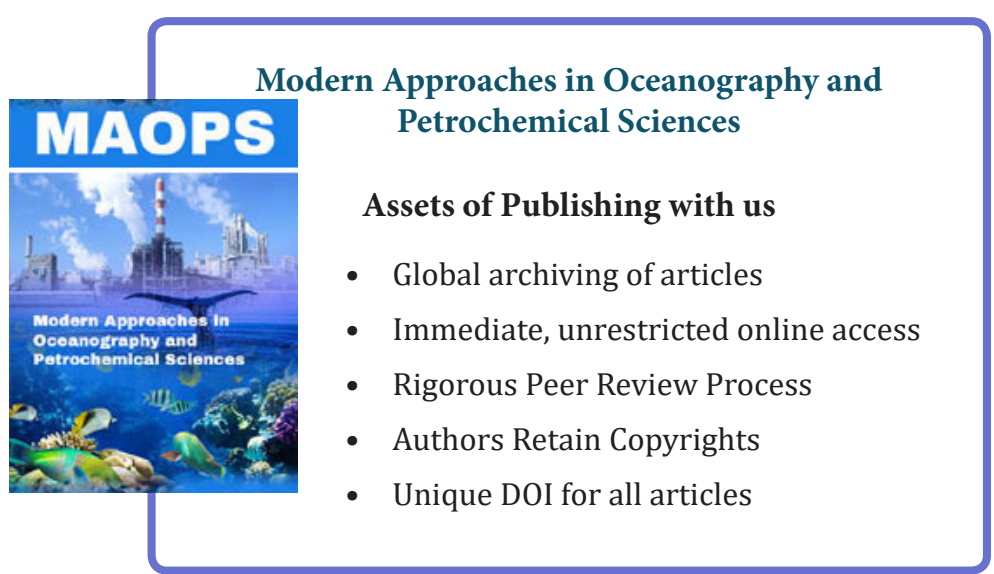

